J. Lake Sci. (湖泊科学), 2011, 23(6): 868-872

http: //www.jlakes.org. E-mail : jlakes@niglas.ac.cn

(c) 2011 by Journal of Lake Sciences

\title{
鄱阳湖沉积物间隙水中磷的含量及其分布特征”
}

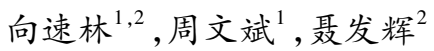 \\ (1: 南昌大学教育部鄱阳湖湖泊生态与生物资源利用重点实验室,南昌 330047) \\ (2: 华东交通大学环境工程系,南昌 330013)
}

\begin{abstract}
摘 要: 根据 2010 年 1 月对鄱阳湖各站点沉积物的采样分析, 研究了鄱阳湖沉积物间隙水中总溶解性磷 (DTP) 与可溶 性正磷酸盐 (DIP) 的含量及其分布特征, 并对各站点表层沉积物间隙水中 DTP 和 DIP 的含量及其沉积物中 TP 与 IP 的含 量进行了相关性分析. 结果表明, 鄱阳湖各站点表层沉积物 $(0-2 \mathrm{~cm})$ 间隙水中 DTP 的平均含量为 $0.134 \mathrm{mg} / \mathrm{L}$, DIP 平均 含量为 $0.082 \mathrm{mg} / \mathrm{L}$. 表层沉积物间隙水中 DTP 与 DIP 含量在空间分布上差异不显著; 而柱状沉积物 $(0-28 \mathrm{~cm})$ 间隙水中 DTP 与 DIP 含量开始随深度的增加呈明显增加趋势, 而后随深度增加而减少. 相关性分析表明, 表层沉积物间隙水中 DIP 与表层沉积物中 IP 相关性不明显, 而表层沉积物中 TP 与其间隙水中 DTP 则具有较好的相关性, 说明沉积物中 TP 可能 是间隙水中 DTP 的重要决定因素.
\end{abstract}

关键词: 鄱阳湖; 沉积物;间隙水; 磷; 分布特征

\section{Phosphorus concentrations and distributions in lacustrine interstitial water of Lake Poyang}

\author{
XIANG Sulin ${ }^{1,2}$, ZHOU Wenbin ${ }^{1} \&$ NIE Fahui ${ }^{2}$ \\ (1: Key Laboratory of Lake Poyang Ecology and Bioresource Utilization of MOE, Nanchang University, Nanchang $330047, P$. \\ R. China) \\ (2: Department of Environment Engineering, East China JiaoTong University, Nanchang 330013, P. R. China)
}

Abstract: The concentrations and distribution of dissolved total phosphorus (DTP) and dissolved inorganic phosphorus (DIP) in the sediment interstitial water from Lake Poyang were determined based on the sampling in January 2010. The results showed that the average DTP and DIP concentrations in the overlying interstitial water of Lake Poyang $(0-2 \mathrm{~cm})$ were $0.134 \mathrm{mg} / \mathrm{L}$ and $0.082 \mathrm{mg} / \mathrm{L}$, respectively, which showed no significant spatial variation between sampling sites. The profiles of DTP and DIP contents in the core sediment interstitial water increased with depth at $0-18 \mathrm{~cm}$ and then decreased with depth at $18-28 \mathrm{~cm}$. For the DIP, no significant correlation was found between interstitial water and sediment. But for the DTP, a certain correlation existed between the surface interstitial water and sediment, indicating that the concentration of TP in the surface sediment can influence the DTP content in the interstitial water.

Keywords: Lake Poyang; sediment; interstitial water; phosphorus; distribution characteristics

湖泊沉积物是氮、磷等营养物质的重要储存库, 同时也是湖泊水体中营养盐的重要内源. 在沉积物氮、 磷等营养盐的内源释放过程中, 沉积物间隙水扮演着重要角色, 是沉积物与水界面营养盐交换的重要介 质 ${ }^{[1-4]}$. 沉积物间隙水中氮、磷含量对上覆水中营养盐供给非常重要, 当间隙水中氮、磷含量超过上覆水中 氮、磷含量时, 溶解的氮、磷就可以释放到上覆水体 ${ }^{[5-6]}$, 从而成为影响湖泊水质的重要因素. 沉积物间隙水 中氮、磷提供了沉积物中生物生长所必须的营养物质, 且间隙水中氮、磷剖面分布是沉积物中有机物质降解 过程的一个敏感指示 ${ }^{[7-8]}$, 其氮、磷含量水平也可直接反映出沉积物环境的优劣, 并在一定程度上影响到底

* 国家自然科学基金项目 (40672159)、江西省科技支撑重点项目 (2010BNA09600) 和江西省自然科学基金项目 (2009GZH0023) 联合资助. 2011-02-28 收稿;2011-04-12 收修改稿. 向速林, 男, 1978 年生, 博士研究生, 讲师; E-mail: slxiang2001@163.com. 
栖生物的生存、发育和组成 ${ }^{[9-10]}$. 因此, 研究湖泊沉积物间隙水中磷含量及分布有助于了解营养盐在沉积物 与水界面的交换过程, 是掌握营养盐生物地球化学循环的重要手段之一 ${ }^{[1,10-11]}$, 并有利于把握磷在沉积物中 所发生的各种过程.

鄱阳湖 $\left(28^{\circ} 24^{\prime}-29^{\circ} 46^{\prime} \mathrm{N}, 115^{\circ} 49^{\prime}-116^{\circ} 46^{\prime} \mathrm{E}\right)$ 位于江西省北部, 长江中下游南岸, 是中国第一大淡水湖, 是一个过水性、吞吐型、季节性浅水湖泊. 随着鄱阳湖区域经济的迅速发展,农药和化肥大量施用, 城镇排污 量和人口的增加使大量营养物质不断流人湖泊, 鄱阳湖富营养化程度日渐增加, 严重制约了区域经济的可 持续发展, 而研究鄱阳湖沉积物间隙水中磷的含量及其分布特征对于认识鄱阳湖富营养化进程具有重要意 义. 国内外学者对湖泊沉积物间隙水中氮、磷分布特征进行了相关的研究 ${ }^{[1,3,6,8,10,12]}$, 对于本研究的开展具有 重要的指示意义. 但由于鄱阳湖是一个过水性、季节性浅水湖泊,湖泊丰枯水期水位相差极大, 且湖流特征 明显, 具有独特的湖泊水环境特征, 从而导致其沉积环境的独特性. 此外, 鄱阳湖接纳了来自上游五大河流 的来水,各河口区由于上游河水的冲刷等作用导致了鄱阳湖各河口区的水环境特征的动态变化,这些独特 的区域环境特征也决定了鄱阳湖与其它湖泊的差异性. 因此,对于鄱阳湖这种过水性、季节性浅水湖泊沉积 物间隙水中磷含量与分布特征研究具有重要意义, 对其它过水性、季节性湖泊沉积物间隙水中营养盐分布 特征的研究具有重要的借鉴意义. 目前,有关鄱阳湖磷的研究主要集中在湖泊水体中磷含量及时空分布特 征,而有关鄱阳湖沉积物间隙水中磷的含量及其分布特征的系统性研究则鲜见报道,而对其它湖泊沉积物 间隙水中营养盐的研究成果中所发现的分布规律也各有不同,因此有必要对鄱阳湖沉积物间隙水中磷的分 布特征进行系统研究和探索. 本文根据鄱阳湖表层及柱状沉积物间隙水样品中磷的分析结果, 探讨了沉积 物间隙水中的总溶解性磷 (DTP) 与可溶性正磷酸盐 (DIP) 含量的空间和垂向分布特征,并分析了表层沉积 物及其间隙水中磷含量的相关性. 本研究的开展对于掌握鄱阳湖营养盐的内源污染机理具有重要意义,并 可为鄱阳湖水体富营养化的控制与治理提供重要的参考依据.

\section{1 材料与方法}

\section{1 样品采集}

在枯水季节 (2010 年 1 月), 即河口或湖泊水面显著下 降时, 在鄱阳湖各人湖河口处或湖滩近岸点水位较浅处设 置 10 个站点 (图 1), 利用柱状采样器 (直径为 $50 \mathrm{~mm}$ ) 采集 厚度约为 $28-30 \mathrm{~cm}$ 的沉积物柱状样品, 在现场按照 $2 \mathrm{~cm}$ 间 隔进行切割分装, 并且在 $4 \mathrm{~h}$ 之内以 $4000 \mathrm{r} / \mathrm{min}$ 的转速离心 $30 \mathrm{~min}$, 吸出上清液, 用孔径为 $0.45 \mu \mathrm{m}$ 的尼龙膜过滤后加人 $\mathrm{HgCl}_{2}$ 固定, 在 $4{ }^{\circ} \mathrm{C}$ 下保存备测. 其中, 用 $2 \mathrm{~cm}$ 间隔分层后 的沉积物分别进行离心获取离心液,用于研究间隙水营养 盐垂直分布, 采用表层 $0-2 \mathrm{~cm}$ 的沉积物进行离心获取离 心液,用于研究间隙水营养盐空间分布.

\section{2 实验方法}

沉积物间隙水中磷的物理状态一般可分为溶解态、悬 浮态及胶体态. 无论是悬浮态或溶解态, 又可分为正磷酸 盐磷、聚合磷酸盐磷和有机磷三种主要形态, 其中溶解态 正磷酸盐是能够被植物吸收的主要形式. 因此, 本研究中 主要探讨沉积物间隙水中总溶解性磷 (DTP) 与可溶性正 磷酸盐磷 (DIP). 鄱阳湖沉积物中形态磷含量及其间隙水 中 DTP 测定采用过硫酸钾消解法; DIP 测定采用钿-锑-抗 分光光度法 ${ }^{[13]}$.

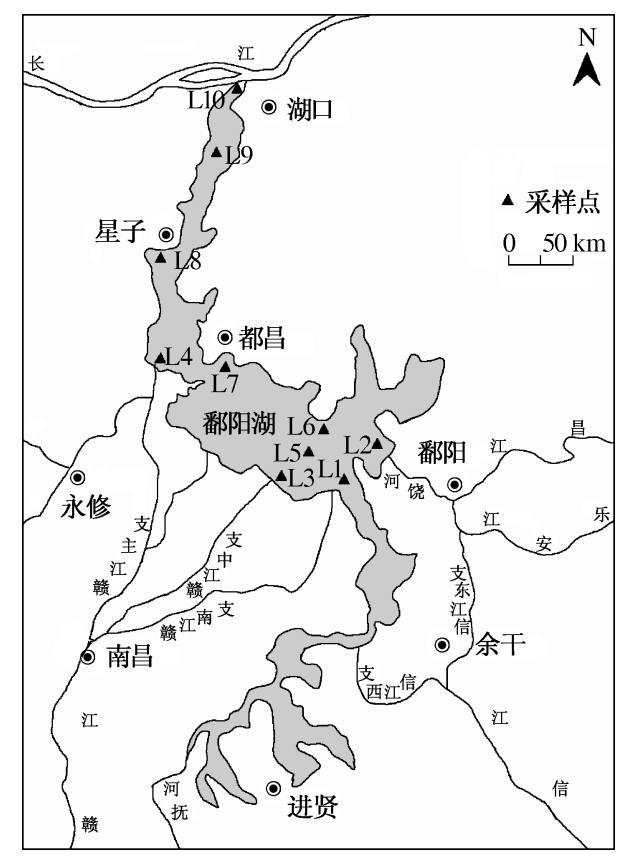

图 1 鄱阳湖沉积物间隙水的采样点分布

Fig. 1 Sampling locations in Lake Poyang sediment interstitial water 


\section{2 结果与讨论}

\section{1 表层沉积物间隙水中磷含量和分布特征}

沉积物间隙水中的营养盐含量水平是沉积物中有机物含量及其分解速率、界面的水动力因素以及底栖 生物的数量等多种因素综合作用的结果 ${ }^{[11]}$, 一般认为, 沉积物间隙水中氮、磷等营养盐含量主要来源于生物 死亡后的一部分碎屑、壳体的分解和陆源物质的溶解, 而且沉积物间隙水中氮、磷含量的高低, 直接影响着 沉积物与上覆水之间营养盐的交换 ${ }^{[6]}$. 鄱阳湖各站点表层沉积物 $(0-2 \mathrm{~cm})$ 间隙水中 DTP 的含量在 $0.101-0.163 \mathrm{mg} / \mathrm{L}$ 之间变动, 平均含量为 $0.134 \mathrm{mg} / \mathrm{L}$, DIP 的含量范围为 $0.057-0.098 \mathrm{mg} / \mathrm{L}$, 平均含量为 $0.082 \mathrm{mg} / \mathrm{L}$.

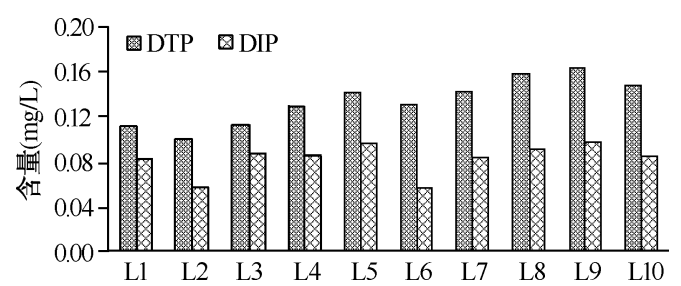

图 2 表层沉积物间隙水中 DTP 与 DIP 含量分布

Fig. 2 Contents of DTP and DIP in sediment interstitial water of Lake Poyang

鄱阳湖各站点表层沉积物间隙水中 DTP 与 DIP 含量的空间分布差异不显著, 其中赣江等河口站点 (L1、L2、L3 与 L4) 中 DTP 与 DIP 含量略低于主湖区 及湖口站点 ( L5、L6、L7、L8、L9 与 L10) (图 2), 其主要 原因可能是河口地区站点湖流运动强烈, 水力冲刷作 用明显,加速了沉积物间隙水中的磷向上覆水的释 放,减少了这些站点沉积物中磷的蓄积量, 从而降低 了沉积物间隙水中 DTP 与 DIP 含量; 而 L5、L6 等站点 则位于小岛屿附近, 受风浪影响相对较小, 水动力作 用较弱,沉积物间隙水中磷的释放作用较弱,且这些

站点也在一定程度上受到周围陆地污染物排放的影响, 从而导致这些站点表层沉积物间隙水中 DTP 与 DIP 含量略高于河口地区; 此外, L7 站点位于人口相对密集区域以及排污口附近, 上游含磷工业、农业和生活污 水的直接排放导致了该监测点上覆水体中磷含量增加, 从而使得该站点沉积物中磷的积累量相对较高; 其 它站点 ( L8、L9、L10) 位于湖区的北部水道区, 湖水较深, 沉积物与水界面间的水动力等作用相对较弱, 有利 于磷等物质的沉积, 从而使得这些站点沉积物间隙水中磷的含量相对更高. 此外, 鄱阳湖表层沉积物间隙水 中 DTP 与 DIP 含量的空间差异也可能与各监测点水生高等植物的分布以及沉积环境有关. 沉积物中磷的释 放与沉积物氧化还原条件密切相关, 一般而言, 沉积物氧化环境会促进沉积物对上覆水体中磷的吸附过程, 而厌氧环境则加速了沉积物中磷的释放过程, 因此影响了表层沉积物间隙水中磷的含量. 站点 L1、L2 与 L3 的表层沉积物间隙水中 DTP 与 DIP 浓度最低, 可能是由于这些站点附近区域大量生长的浮游植物消耗了上 覆水体中的磷, 引起了上覆水体与间隙水较大的浓度差, 从而使得沉积物间隙水中磷的释放速率增加, 并且 这些站点沉积物与水界面的还原环境也加速了表层沉积物间隙水中磷向上覆水的转移, 因而降低了这些站 点表层沉积物间隙水中 DTP 与 DIP 浓度; 站点 L8、L9 与 L10 的表层沉积物间隙水中 DTP 与 DIP 的高含量可 能与这些站点沉积物所处的氧化环境及沉积物自身特性有关, 通过对获取的沉积物样品的定性比较可知, 相对其它站点, 这些站点沉积物颗粒的粒径相对较细, 有利于其对上覆水体中磷的吸附, 从而也使得这些站 点表层沉积物间隙水中磷含量相对其它站点较高.

\section{2 柱状沉积物间隙水中磷的垂向分布特征}

沉积物间隙水中营养盐的剖面分布趋势是沉积物中有机物质降解过程与生源要素生物地球化学循环 过程的一个敏感指示, 了解沉积物间隙水中营养盐的分布剖面有助于掌握沉积物中有机物矿化作用及测定 沉积物与水界面营养盐交换通量 ${ }^{[7-8]}$. 鄱阳湖各个监测点柱状沉积物 $(0-28 \mathrm{~cm})$ 间隙水中 DTP 平均含量范 围为 $0.120-0.174 \mathrm{mg} / \mathrm{L}$, DIP 平均含量范围为 $0.067-0.111 \mathrm{mg} / \mathrm{L}$.

鄱阳湖各监测点柱状沉积物间隙水中 DTP 与 DIP 的含量随深度的变化趋势基本一致, 在表层沉积物与 水界面附近, 其浓度较低, 与上覆水中磷的浓度相差不大 (图 3). 随着深度的增加, 其含量开始逐步增加, 但 在达到一定深度后又开始随着深度的增加呈减小的趋势. 沉积物间隙水中的 DTP 与 DIP 可以滞留在沉积物 
中,也可转移到上覆水体中而被浮游植物吸收利用,其浓度的垂向分布可能受到有机物的分解、铁氧化物浓 度以及微生物活动等各种因素的影响. 鄱阳湖柱状沉积物间隙水中磷的剖面变化特征与 Williams 等研究结 果基本一致 ${ }^{[14]}$,产生这种变化特征的主要原因是在沉积物与水界面以下的氧化带中,有一层没有完全结晶 的对磷具有较强吸附能力的铁的氢氧化物, 由于铁的氢氧化物的吸附作用,导致表层沉积物间隙水中磷的 含量降低. 而随着深度的增加, 铁的氢氧化物的还原作用则逐步加强, 降低了其对磷的吸附作用, 从而引起 磷的含量增加. 而在到达一定深度后, 深层沉积物中磷的浓度越来越低, 从而导致可溶人间隙水中磷的浓度 也逐渐降低, 因此间隙水中磷浓度随沉积深度增加而降低 ${ }^{[14-15]}$. 此外, 湖泊底层沉积物相对比较密实, 受到 上覆水动力扰动及其他扰动作用相对较小, 存在活性的有机碎屑减少, 有机质含量降低, 沉积物中微生物活 动亦减少,所以湖泊底层沉积物间隙水中磷含量也相应降低 ${ }^{[12]}$. 沉积物间隙水中营养盐的垂向分布差异表 明了沉积物间隙水中磷具有向上覆水体释放的趋势.
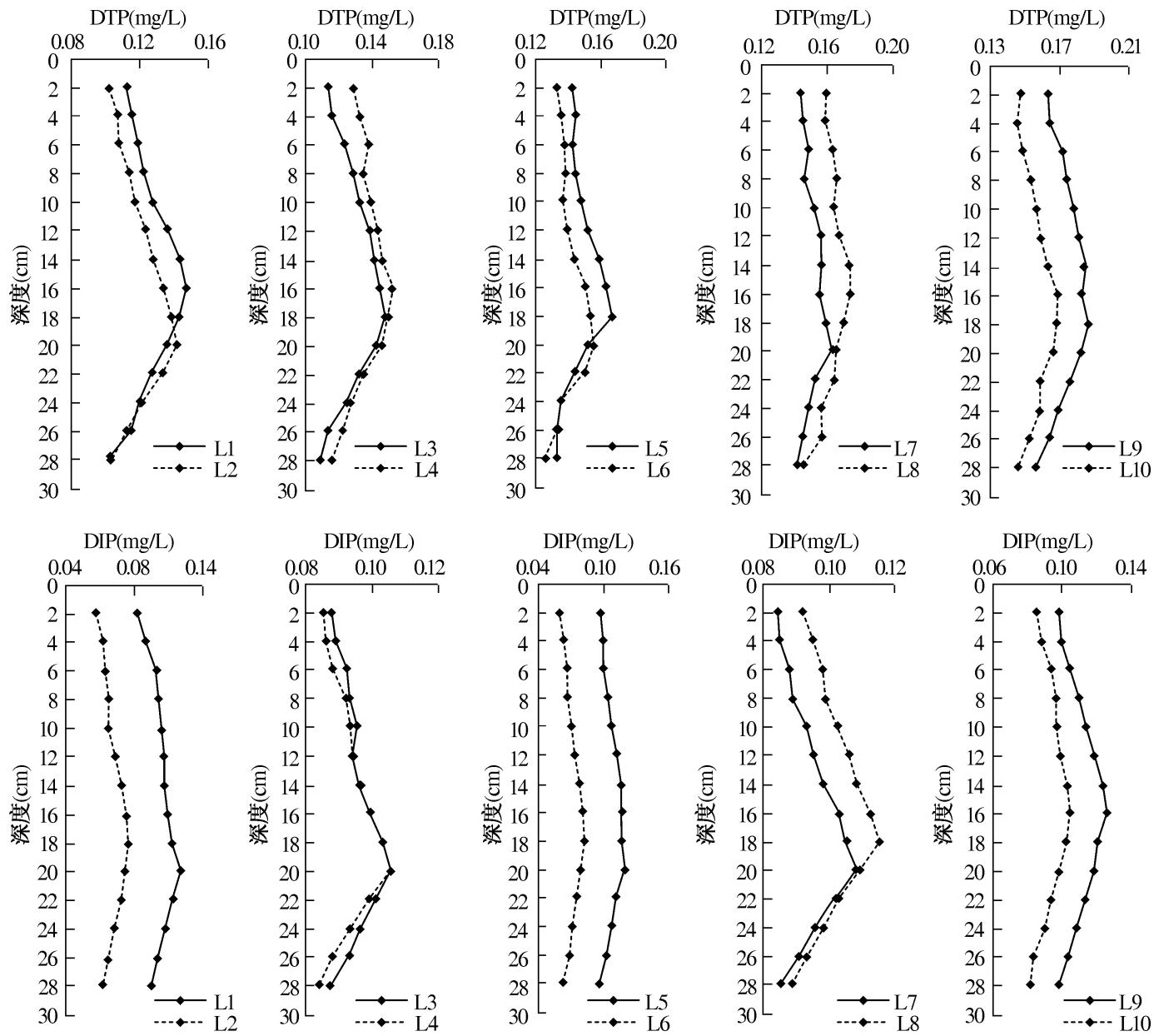

图 3 沉积物间隙水中 DTP 与 DIP 含量的垂向分布

Fig. 3 Profile distributions of DTP and DIP in sediment interstitial water of Lake Poyang

\section{3 表层沉积物及间隙水中磷的相关性分析}

鄱阳湖各监测点表层沉积物中 TP 的含量与其间隙水中 DTP 含量具有较好的相关性,而各监测点表层 沉积物中 IP 含量与其间隙水中 DIP 含量相关性不明显 (图 4), 说明沉积物中 TP 可能是间隙水中 DTP 的重 要决定因素. 

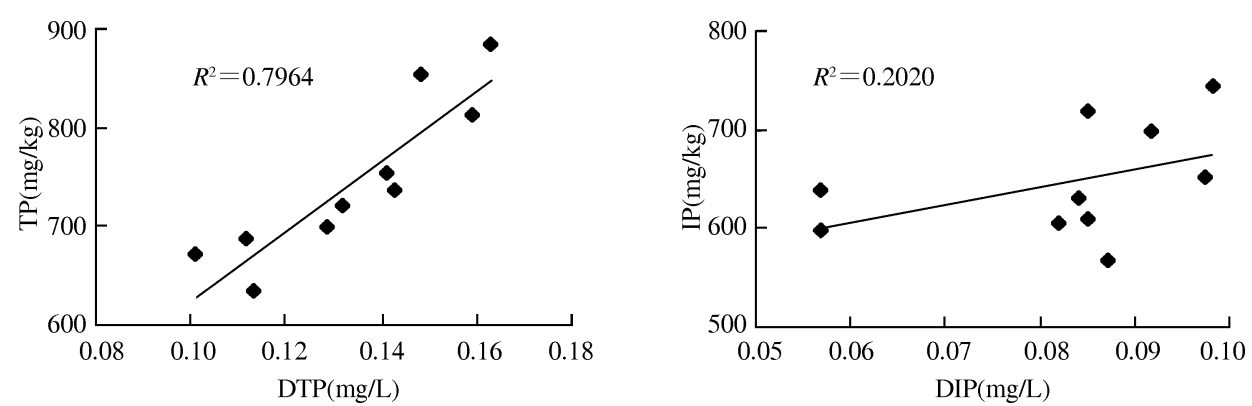

图 4 鄱阳湖各监测点表层沉积物 TP 和 IP 含量与间隙水中 DTP 与 DIP 含量的相关关系

Fig. 4 The corrections of TP and IP in surface sediments and DTP and DIP in interstitial water of Lake Poyang

\section{3 参考文献}

[ 1 ] 胡 俊, 刘永定, 刘剑形. 滇池沉积物间隙水中氮、磷形态及相关性的研究. 环境科学学报, 2005, 25(10): 13911396.

[2] 王雨春, 万国江, 尹澄清. 红枫湖、百花湖沉积物全氮、可交换态氮和固定铵的赋存特征. 湖泊科学, 2002,14 (4) : 301-309.

[ 3 ] Barbara S, Stefan P, Yoram A et al. Phosphorus mobility in interstitial waters of sediments in Lake Kinneret, Israel. Hydrobiologia , 1990, 207 : 167-177.

[ 4 ] 罗玉兰, 徐渘, 曹 忠. 秦淮河底泥及间隙水氮磷垂直分布及相关性分析. 农业环境科学学报, 2007, 26 (4): 1245-1249.

[ 5 ] Kalervo M, Liisa T. Pore water nutrient profiles and dynamics in soft bottoms of the northern Baltic Sea. Hydrobiologia, 2003, 492: 43-53.

[6] 张水元, 刘瑞秋, 黎道丰. 保安湖沉积物和间隙水中氮和磷的含量及其分布. 水生生物学报, $2000,24(5)$ : $434-438$.

[ 7 ] 高 否, 李道季, 余立华等. 长江口崇明东滩沉积物间隙水中营养盐剖面及其数学模拟. 沉积学报, 2006,24 (5) : $722-731$.

[8] 高 碟, 李道季, 王延明等. 长江口最大浑浊带沉积物间隙水中营养盐剖面研究. 环境科学, 2006, 27 (9) : 17441752.

[ 9 ] Li QM, Zhang W, Wang XX et al. Phosphorus in interstitial water induced by redox potential in sediment of Dianchi Lake, China. Pedosphere, 2007, 17 (6) : 739-746.

[10] 范成新, 杨龙元, 张 路. 太湖底泥及其间隙水中氮磷垂直分布及相关性分析. 湖泊科学, 2000, 12 (4): 359-366.

[11] 周伟华, 吴云华, 陈绍勇. 南沙群岛海域沉积物间隙水营养盐 (氮、磷、硅) 的研究. 热带海洋学报, 2001, 20(4): 49-55.

[12］李 宝, 范成新, 丁土明等. 滇池福保湾沉积物磷的形态及其与间隙水磷的关系. 湖泊科学, 2008, 20 (1): 27-32.

[13] 金相灿, 屠清瑛. 湖泊富营养化调查规范(第二版). 北京: 中国环境科学出版社, 1990.

[14] Williams LD, Jaquet JM, Thomas RL. Forms of phosphorus in the surficial sediments of lake. Journal of the Fisheries Research Board of Canada, 1976, 33: 413-429.

[15] 翁焕新, 刘云峰, Armstrong D. 滨海沉积物和间隙水中磷的研究. 环境科学学报, 1997, 17(2):148-153. 